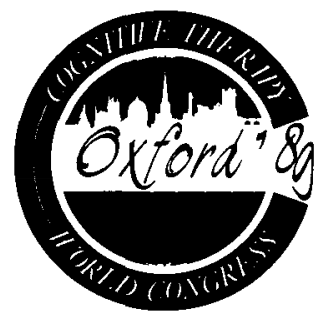

Congress Committee

David M Clark Chair

Paul Salkovskis Secretary

Gillian Butler Treasurer

Michael Gelder

Aaron T Beck

Melanie Fennell

Ann Hackmann

Rosemary Jones

John Marzillier

Wendy Ball Organiser

Rod Holland Consultant

\section{International Advisory}

Committee

John Bancroft

David Barlow

Aaron T Beck

Miklos Biro

In Blackburn

Tom Borkovec

Jean Cottraux

Keith Dobson

Gary Emery

Paul Emmelkamp

Edna Foa

David Garner

Michael Gelder

Marvin Goldfried

Christina Goytia

Richaró Hallam

Iver Hand

Keith Hawton

Steve Hollon

Marcel van den Hout

Derek Johnston

Philip Kendall

Anthony Kidman

Maria Kopp

Maria Kovacs

Xue-Rong Li

Giovanni Liotti

Paul Martin

John Marzillier

Andrew Mathews

Donald Meichenbaum

Yukata Ono

Lars-Goran Öst

Eugene Paykel

Carlo Perris

Stanley Rachman

A John Rush

Brian Shaw

Sue Spence

John Teasdale

Dennis Turk

Fraser Watts

JMark Williams

Jeffrey Young
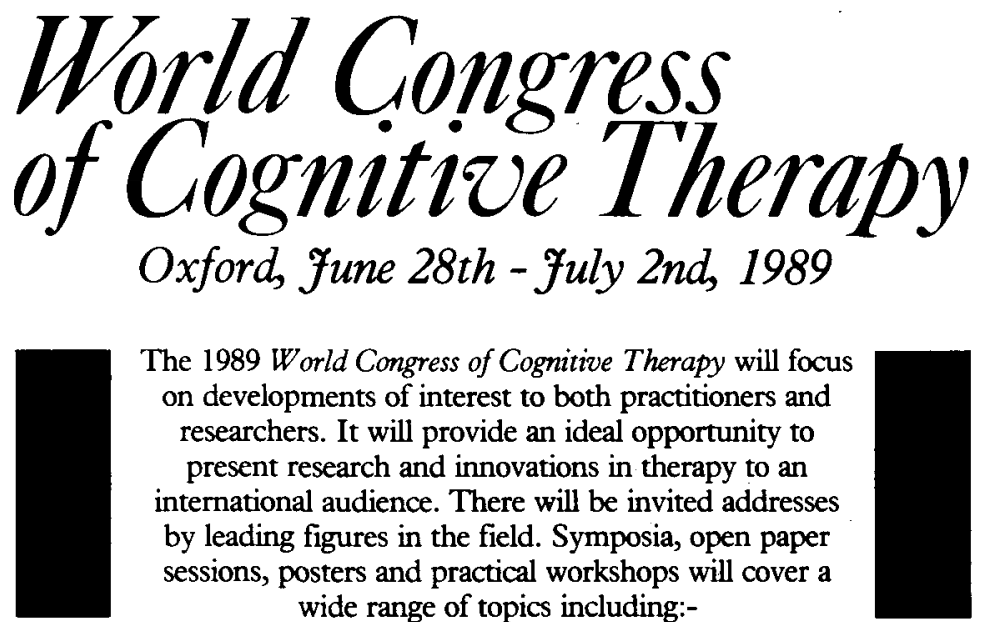

The 1989 World Congress of Cognitive Therapy will focus on developments of interest to both practitioners and researchers. It will provide an ideal opportunity to present research and innovations in therapy to an international audience. There will be invited addresses by leading figures in the field. Symposia, open paper sessions, posters and practical workshops will cover a wide range of topics including:-

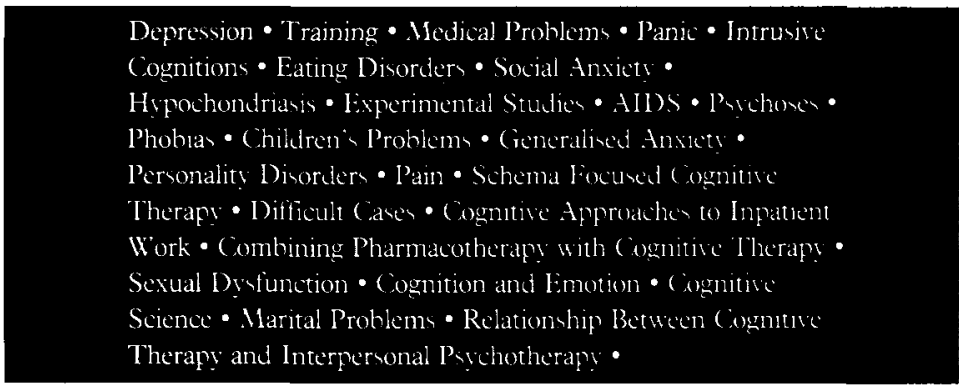

- Speakers already confirmed include:

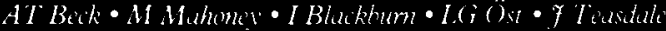

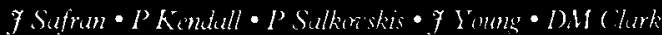

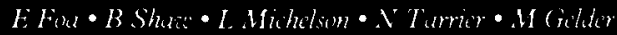

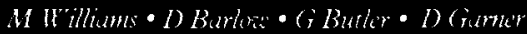

There will be an extensive social programme and a number of visits to places of interest in and around Oxford, the oldest University in Britain

\section{Open Paper and Poster submissions} are invited by 31 st December 1988 (Papers) 30th April 1989 (Posters)

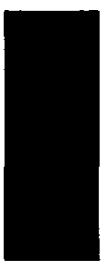

Outline proposals (including a 200 word abstract) should be sent to the address below

$$
\begin{gathered}
\text { Apply now for } \\
\text { Registration Forms }
\end{gathered}
$$

to

World Congress of Cognitive Therapy,

Department of Psychiatry, University of Oxford,

Warneford Hospital, Oxford OX3 7JX, UK 


\section{国WILEY}

\section{Beyond Sexual Abuse \\ Therapy with Women who were Childhood Victims}

D. JEHU, University of Leicester, UK

This is the first detailed manual to present a systematic and comprehensive approach to the assessment and treatment of a wide range of psychosocial problems of women who were sexually abused in childhood. These problems are described and detailed guidelines are provided for practitioners who may wish to implement and develop the author's intervention approach with their own clients.

Wiley Series in Psychotherapy and Counselling

0471919136 350pp August 1988

634.95/\$70.00

\section{Self, Symptoms and}

\section{Psychotherapy}

Edited by N. CHESHIRE, Ysbyty Gwynedd, Bangor, Wales, UK and H. THOMAE, University of Ulm, West Cermany

This volume examines the way in which disturbances in Self functions (such as identity-feelings, self-esteem, individuation and agency) may underlie the familiar neurotic disorders of depression, anxiety, obsessions, phobias and psychosomatic malfunctions (as well as certain personality traits and defects), the symptoms of which are presented every day to psychiatrists, clinical psychologists, psychoanalysts et al., and at which various types of psychotherapy are directed.

Wiley Series in Methods in Psychotherapy

0471905488 312pp September 1987

$\mathbf{E 5} .95 / \mathbf{\$ 7 5 . 0 0}$ iley books are available through your
bookseller. Alternatively, order direct from Wiley (payment to John Wiley \& Sons Ltd). Credit card orders accepted by telephone (0243) 829121 or FREEFONE 3477 (UK only).

JOHN WILEY \& SONS LTD

BAFFINS LANE - CHICHESTER - W. SUSSEX PO19 1UD 
1. Submission. Articles written in English and not submitted for publication elsewhere, should be sent to The Editors, Behavioural Psycbotherapy, Department of Psychiatry, University of Oxford, Warneford Hospital, Oxford OX3 7JX, U.K.

2. Manuscript preparation. Four complete copies of the manuscript must be submitted. Original figures should be supplied at the time of submission. Articles must be typed double-spaced throughout on standard sized paper (preferably A4) allowing wide margins all round. Where unpublished material, e.g. behaviour rating scales, therapy manuals, etc is referred to in an article, copies should be submitted to facilitate review.

Manuscripts will be sent out for review exactly as submitted. Authors who want a blind review should mark two copies of their article "review copy" omitting from these copies details of authorship.

Abbreviations where used must be standard. The Système Internationale (SI) should be used for all units; where metric units are used the SI equivalent must also be given. Probability values and power statistics should be given with statistic values and degrees of freedom [e.g. $F(1,34)=123 \cdot 07, P<0 \cdot 001$ ], but such information should preferably be included in tables rather than the main text.

Spelling must be consistent within an article, either using British usage (The Shorter Oxford English Dictionary), or American usage (Webster's New Collegiate Dictionary). However, spelling in the list of references must be literal to each original publication.

Details of style not specified here may be determined by reference to the Publication Manual of the American Psychological Assaciation.

Articles should conform to the following scheme:

(a) Title page. The title should phrase concisely the major issues. Author(s) to be given with departmental affiliations and addresses, grouped appropriately. A running head of no more than 40 characters should be indicated.

(b) Summary. This should summarize the article in no more than 200 words.

(c) Text. This should begin with an introduction, succinctly introducing the point of the paper to those interested in the general area of the journal. References within the text should be given in the form Jones and Smith (1973). When there are three or more authors the first citation should include all authors, subsequent citations should be given as Williams et al. (1973). Authors with the same surname should be distinguished by their initials. The approximate positions of tables and figures should be indicated in the text. Footnotes should be avoided where possible.

(d) Reference note ( $s$ ). A list of all cited unpublished or limited circulation material, numbered in order of appearance in the text, giving as much information as possible about extant manuscripts.

(e) References. All citations in the text should be listed in strict alphabetical order according to surnames. Multiple references to the same author(s) should be listed chronologically, using a, b, etc., for entries within the same year. Formats for journal articles, books and chapters should follow these examples:

BeCKER, M. R. and GreEN, L. W. (1975). A family approach to compliance with medical treatment: A selective review of the literature. International Journal of Health Education 18, 173-182. THORP, R. G. and WETZEL, R. J. (1969). Behaviour Modification in the Natural Environment. New York: Academic Press.

Roskies, E. and LAzArus, R. S. (1980). Coping theory and the teaching of coping skills. In Bebavioural Medicine: Changing Health Lifestyles, P. O. Davidson and S. M. Davidson (Eds), New York: Brunner/Mazel.

(f) Footnotes. The first, and preferably only, footnote will appear at the foot of the first page of each article, and subsequently may acknowledge previous unpublished presentation (e.g. dissertation, meeting paper) financial support, scholarly or technical assistance, or a change in affiliation. Its concluding (or only) paragraph must be the name and full mailing address of the author to whom reprint requests or other inquiries should be sent.

(g) Tables. Tables should be numbered and given explanatory titles.

(h) Figure captions. Numbered captions should be typed on a separate page.

(i) Figures. Original drawings or prints must be submitted for each line or half-tone illustration. Figures should be clearly labelled.

3. Proofs, Reprints and Copyright. Proofs of accepted articles will be sent to authors for the correction of printers' errors; author's alterations may be charged. Authors submitting a manuscript do so on the understanding that if it is accepted for publication exclusive copyright of the paper shall be assigned to the Society. In consideration of the assignment of copyright, 25 copies of each paper will be supplied. Further reprints may be ordered at extra cost; the copyright assignment form and the reprint order form will be sent 


\section{CONTENTS}

Power, K. G., Jerrom, D. W. A., Simpson, R. J., Mitchell, M. J. and Swanson, V. A Controlled Comparison of Cognitive-Behaviour Therapy, Diazepam and Placebo in the Management of Generalized Anxiety

Watts, F. N. Attentional Strategies and Agoraphobic Anxiety ...

SingH, A. C. and Bilsbury, C. D. Measuring Levels of Experiential States in Clinical Applications by Discan: A Discretized Analog Method

LINDSAY, W. R. and BATY, F. J. Group Relaxation Training with

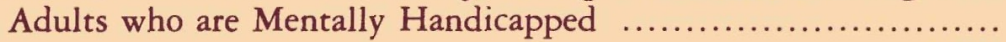

JeHU, D. Sexual Dysfunctions Among Women Clients who were

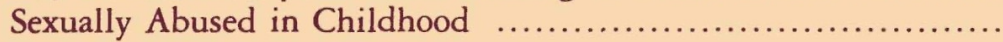

Eves, F. and TAta, P. Phasic Cardiac and Electrodermal Reactions to Idiographic Stimuli in Obsessional Subjects .......

Clinical/Brief Reports

Sturmey, P. and Crisp, A. G. A Component Analysis of the Room Manager Role 